\title{
O SELF-BOX COMO EXPERIMENTO NA ATUAÇÃO DO GESTALT-TERAPEUTA COM ADOLESCENTES
}

\author{
The Self-Box as an Experiment in Gestalt-therapy with Adolescents \\ El Self-Box como Experimento en el desempeño de lo gestalt terapeuta com los adolescentes
}

DEYSEANE MARIA ARAÚJO LIMA

\begin{abstract}
Resumo: A constituição da adolescência é um período repleto de transformações, de autoconhecimento e de conflitos, que possibilitam a busca de psicoterapia para os adolescentes. O artigo tem como intuito compreender o uso do self-box (a caixa do eu) como experimento na clínica gestáltica com adolescentes. A abordagem metodológica do estudo é a pesquisa qualitativa com um enfoque na pesquisa bibliográfica, recorrendo aos materiais já elaborados sobre o tema. Na clínica com adolescentes na Gestalt-terapia, é essencial que possamos usar experimentos que promovam o estabelecimento da relação terapêutica, o interesse pelo tratamento e a disponibilidade para abordar o seu sofrimento, amenizando as resistências. O uso self-box sugere que o adolescente selecione objetos que o identificam em uma caixa, retratando as suas experiências e vivências marcantes. Neste sentido, o uso do self-box como experimento na clínica gestáltica promove aos adolescentes resgatar fatos sobre a sua infância, compreender a sua família, perceber suas atitudes, entrar em contato com seus sentimentos e suas emoções, propiciar novas percepções e reflexões sobre a sua existência, entre outros. É importante realizarmos estudos e investigações que possam trazer novas contribuições para a prática clínica na Gestalt-terapia com adolescentes, sendo uma oportunidade de compartilhar experiências profissionais e reflexões teóricas.
\end{abstract}

Palavras-chave: Adolescência; Gestalt-terapia; Experimentos; Prática Clínica; Self-Box.

\begin{abstract}
The adolescence is a period of intense transformations, self-knowledge and conflicts. This enables a search for psychotherapy embracing adolescents. The aim of this paper is to understand the experimental use of self-box in Gestalt-Therapy with adolescents. The methodological approach of the study is qualitative, with a focus on a bibliographic research that survey previous publications on the subject. For a successful clinical practice in Gestalt Therapy, the paper points out as crucial the use of experiments that promote the establishment of the therapeutic relationship, interest in the treatment, willingness to address painful experiences, and the loosening of resistances. The self-box invites the adolescent to select objects that portray their most meaningful experiences and to organize such objects in a box. In this sense, the use of self-box as an experiment in Gestalt clinic allows adolescents to recover facts about their childhood, to understand their family, to perceive their attitudes, to get in touch with their feelings and their emotions, to provide new insights and reflections on their existence, among others. It is important to carry out studies and investigations that bring new contributions to the clinical practice in Gestalt-Therapy with adolescents, providing an opportunity to share professional experiences and theoretical reflections.
\end{abstract}

Keywords: Adolescent; Gestalt-Therapy; Experiments; Clinical practice; Self-Box.

Resumen: La constitución de las adolescencias es un período repleto de transformaciones, de autoconocimiento y de conflictos, que posibilitan la búsqueda de psicoterapia para los adolescentes. El artículo tiene como objetivo comprender el uso del "self-box" (la caja del yo) como experimento en la clínica gestáltica con adolescentes. El enfoque metodológico del estudio es la investigación cualitativa con un enfoque en la investigación bibliográfica, recurriendo a los materiales ya elaborados sobre el tema. En la clínica con adolescentes en la Gestalt-terapia, es esencial que podamos utilizar experimentos que promuevan el establecimiento de la relación terapéutica, el interés por el tratamiento y la disponibilidad para abordar su sufrimiento, amenizando las resistencias. En la psicoterapia, el uso "self-box" posibilita que el adolescente seleccione objetos que lo identifican en una caja, retratando sus experiencias y vivencias importantes. En este sentido, el uso del "self-box" como experimento en la clínica gestáltica posibilita a los adolescentes rescatar hechos sobre su infancia, comprender a su familia, percibir sus actitudes, entrar en contacto con sus sentimientos y sus emociones, propiciar nuevas percepciones y reflexiones sobre la vida Su existencia, entre otros. Es importante realizar estudios e investigaciones que puedan traer nuevas contribuciones a la práctica clínica en la Gestalt-terapia con adolescentes, siendo una oportunidad de compartir experiencias profesionales y reflexiones teóricas.

Palabras clave: Adolescentes; Gestalt-terapia; Experimentos; Práctica Clínica; Self-Box.

\section{Introdução}

O artigo apresenta como objetivo principal discutir o uso do self-box como experimento na atuação do gestalt-terapeuta com adolescentes. Para que isto seja possível, fizemos uma discussão sobre a constituição da adolescência, o uso dos experimentos e o conceito de self na Gestalt-terapia.
A Gestalt-terapia é uma abordagem psicológica que apresenta uma teoria e uma prática baseada na pessoa em sua relação com o mundo com o foco na autorregulação do organismo em prol da satisfação das suas necessidades físicas e psicológicas e atualizar novos ajustamentos criativos com o contexto social.

A concepção de pessoa na Gestalt-terapia é de ser criativo, espontâneo, autêntico, livre para es- 
colher e responsável pelas conseqüências de suas escolhas. Sendo necessário conhecer a forma de funcionamento do sujeito com o mundo e consigo mesmo, ou seja, a maneira que o sujeito se organiza em suas relações sociais, afetivas, comunitárias e organizacionais (Ribeiro, 2011).

A pessoa pertence a um campo constituído pelas relações sociais com outros sujeitos e com o mundo, em que é transformada por esta interação, em suma, é um ser de relação. Desta forma, o sujeito transforma-se à medida que é modificado pela realidade. Então, é um ser de relação permanente com o mundo e com os outros sujeitos, que visa satisfazer as suas necessidades e autorregular-se nesta relação, buscando assim a equilibração (homeostase).

De acordo com Perls (2011), a Gestalt-terapia é uma abordagem terapêutica experiencial, pois convidamos os nossos clientes a re-experienciar suas situações inacabadas no aqui e agora. Isso implica que o cliente pode perceber a sua respiração, os seus gestos, a sua entonação de voz, as suas emoções, a suas expressões faciais, os seus pensamentos, entre outros.

Para Ribeiro (2006, p. 109), “a Gestalt-terapia, como permissão para criar, encontra na possibilidade de experimentar uma de suas particulares riquezas metodológicas".

Esta abordagem convida o psicoterapeuta e o cliente a construírem uma relação baseada na criatividade, na experimentação, na escuta autêntica e no acolhimento, com um enfoque na transformação de si mesmo, do outro e do mundo.

A Gestalt-terapia é uma versão integrada da fenomenologia e do behaviorismo. Temos uma orientação semelhante à da fenomenologia porque respeitamos a experiência interior do indivíduo: o trabalho terapêutico baseia-se na perspectiva do próprio cliente. Ao mesmo tempo, modificamos comportamentos concretos de maneira graduada e cuidadosamente articulada. Com isso, uma das qualidades singulares da Gestalt-terapia é a ênfase na modificação do comportamento de uma pessoa, dentro da própria situação terapêutica. Essa modificação comportamental sistemática, quando brota da experiência pessoal do cliente é chamada de experimento (Zinker, 2007, p. 141).

Em relação à adolescência, para o Estatuto da Criança e do Adolescente, Lei $\mathrm{n}^{\circ}$ 8.069, de 13 de julho de 1990, o adolescente é considerado um sujeito de deveres e de direitos em relação à nossa sociedade. Este período é compreendido dos 12 anos aos 18 anos incompletos, que considera o indivíduo em formação (Brasil, 2005).

$\mathrm{Na}$ atuação do gestalt-terapeuta com adolescentes, o psicoterapeuta deve perceber como acontece as interrupções no contato do cliente com o seu mundo e como ocorre o processo contínuo de conscientização em relação a este fenômeno, gerando assim energia para superar os conflitos provenientes do âmbito escolar, familiar e pessoal. No trabalho com adolescentes, percebemos a necessidade de usar ex- perimentos para promover o diálogo entre psicoterapeuta e cliente, para facilitar a awareness, propiciar a compreensão de si mesmo e integrar as polaridades. É fundamental que o psicoterapeuta possa conhecer e se apropriar dos experimentos para conduzir um trabalho ético com adolescentes, como por exemplo, a cadeira vazia, o movimento corporal, a amplificação, a fantasia dirigida, o self-box.

Desta forma, o presente artigo aborda o uso do self-box como um experimento para trabalhar com adolescentes na clínica gestáltica. $\mathrm{Na}$ construção deste artigo, fizemos uma discussão sobre a constituição das adolescências para a Gestalt-Terapia, falamos da clínica gestáltica com adolescentes, abordamos o uso de experimentos na Gestalt-Terapiac e, finalmente, buscamos aprofundar o enfoque em um experimento para trabalhar com os adolescentes na clínica: o self-box, com articulação entre a teoria e a prática ilustrada com exemplos de casos clínicos.

Neste artigo, a metodologia empregada foi de abordagem qualitativa com enfoque na pesquisa bibliográfica, que se caracteriza de acordo com Lima e Mioto (2007) no estudo dos materiais, dos artigos e dos livros já produzidos sobre o tema a ser investigado, buscando assim um aprofundamento e novas reflexões teóricas sobre o assunto.

\section{Adolescer: Reflexões sobre o desenvolvimento e a prática clínica na Gestalt-terapia}

Neste tópico, fizemos uma reflexão sobre a constituição da adolescência na Gestalt-Terapia, com um enfoque na historicidade do termo, da contribuição da psicanálise, das características desta etapa e as especificidades deste período na abordagem gestáltica, realizando uma interface com a Psicologia do Desenvolvimento. Também abordamos o funcionamento da clínica gestáltica com adolescentes: os primeiros atendimentos, a orientação à família e a relação terapêutica.

\subsection{A Constituição da Adolescência na Gestalt- terapia}

No começo do século XX, Stanley Hall introduziu os estudos da adolescência como objeto de estudo da psicologia e como um período de conflitos e tormentas em relação à sexualidade. Deste a sua origem o termo está vinculado ao sofrimento e a patologização do ser adolescente. Na constituição da adolescência, percebemos a relevância das contribuições psicanalíticas para a Psicologia do Desenvolvimento, com a produção do livro "Adolescência Normal: um enfoque psicanalítico", que apresenta colocações e afirmações essenciais para o entendimento das dificuldades e das possibilidades da adolescência. Sendo um período complexo para assinalar o que é saudável e o patológico para os adolescentes, pois as crises sofridas neste momento podem ser consideradas saudáveis (Aberastury \& Knobel, 1981).

As características da adolescência são, de acordo com Aberastury e Knobel (1981): a busca 
de si mesmo, a tendência grupal, a necessidade de intelectualizar e fantasiar, a sexualidade, a deslocalização temporal, a atitude social reivindicatória, as crises religiosas, as contradições de conduta, a separação progressiva dos pais e as flutuações de estado de humor e de ânimo.

Para Erik Erikson (1987), ainda na vertente psicanalítica, a constituição da identidade do adolescente preconiza os interesses, as formas de ser, as escolhas profissionais, a identificação com os grupos de amigos, entre outros. Sendo um período de conflitos e confusão de papéis. Consoante com este pensamento, Outeiral (1994) remete-se ao termo adolescer, ao enfatizar o processo de crescimento e de constituição da identidade dos adolescentes. Embora, pautado por adoecimento no sentido de sofrimento emocional.

Dialogando com esta caracterização, o adolescer na Gestalt-terapia, para Zanella e Antony (2016), constitui-se em uma fase de desenvolvimento com diversos paradoxos e contradições. Sendo um momento de mudança corporal e ressignificação da relação com os pais e com os amigos. Nesta vivência, podem surgir sentimentos como ansiedade, tristeza e insegurança.

Diante da concepção de ser humano e de mundo da Gestalt-terapia, compreendemos a adolescência não como um período fixo e determinado em formas universais, lineares e padronizantes, mas sim como uma maneira singular de ser com o mundo. Assim, não percebemos apenas como uma fase de transição, mas como um período de desenvolvimento relevante para a constituição humana, que é vivenciada de uma forma singular.

Desta forma, "isso sugere uma visão de adolescência como um fenômeno global que integra 'num todo singular' as diversas forças do ser-no-campo e não como mera latência em direção à maturidade" (Baroncelli, 2012, p. 193). A adolescência é considerada como um período de desenvolvimento que envolve elementos biológicos, mas são perpassados por questões históricas, psicológicas, sociais, econômicas e políticas. Há uma compreensão holística do ser adolescente. Assim, percebemos a constituição da adolescência na atualidade, para Baroncelli (2012, p. 192), “ser adolescente é, portanto, sê-lo num determinado corpo, mas também numa determinada sociedade, etnia, classe social, cultura, família e para determinada pessoa que vai significar todos estes aspectos de formas sempre únicas”.

$\mathrm{Na}$ relação entre família e adolescente, para Oaklander (1980), por um lado, há uma dificuldade dos pais em considerar o crescimento dos filhos; epor outro, há uma necessidade por independência e liberdade por parte do adolescente. Neste sentido, torna-se necessário dialogar com os filhos e negociar os limites.

Zanella e Zanini (2016) afirmam que os adolescentes podem questionar os valores e as concepções de sua família que foram introjetados durante a infância. Apresentam uma postura egocêntrica, voltando-se para os seus interesses e os seus gostos a partir da identificação com os grupos sociais. Há uma fusão entre os adolescentes e estes grupos sociais, havendo assim a necessidade de compartilhar gostos e formas de se comportar. Para Baroncelli (2012), a fronteira do contato do adolescente está se constituindo e amadurecendo, ou seja, ele está percebendo o limite (a sua forma de proteção) e a sua forma de entrar em contato com a família, a escola e sociedade. De acordo com Perls (2011), a fronteira do contato é a maneira como o ser humano interage com o meio, em que ocorre o contato, é um momento de possibilidades e de limites.

Nesta lógica, a Gestalt-terapia em interface com a Psicologia do Desenvolvimento, considera que a adolescência são processos sucessivos e contínuos de ajustamentos criativos que acontecem na relação com o meio ao longo do tempo. Sendo necessário, então, que a família também possa se reconfigurar diante das mudanças na vida de seu filho, abrindo possibilidade para estabelecer uma nova relação com ele. Esta relação pode ser baseada em outras necessidades, como por exemplo, a sexualidade, o amor, a escolha profissional, a negociação de limites, entre outros.

Segundo Cardella (2014), podemos definir o ajustamento criativo na abordagem gestáltica como o estabelecimento do contato entre o sujeito e o mundo, com o intuito da autorregulação. Desta forma, não se refere a uma adaptação algo já existentes, mas sim promover uma transformação do ambiente com o uso de novos recursos e novas formas de atuar com mundo, com o outro e consigo mesmo, caracterizando-se assim como um processo saudável.

O processo de mudança naturalmente vivido pelo adolescente também pode ser entendido como um modo de se ajustar criativamente. Ele precisa dar conta de uma transformação corporal, passando de um corpo infantil para um corpo adulto, construir sua própria identidade frente às expectativas de seus pais e lidar com pais que ainda se comportam como pais da infância. Esse ajustamento é que vai permitir que o adolescente se adapte à sua nova identidade e perceba como se colocar no mundo novo. (Silva, 2015, p. 62)

No atendimento psicoterápico na Gestalt-terapia, os adolescentes são considerados em constante processo de ajustamento criativo, pois estão se recriando e se reconhecendo a partir das interações com o mundo e das diversas transformações deste período de desenvolvimento.

Nesta perspectiva, o trabalho do psicoterapeuta com adolescentesobjetiva a reflexão sobre situações inacabadas da infância, as manifestações sexuais, o interesse pelos grupos, a relação com a família, a percepção do seu crescimento, entre outros.

\subsection{A Clínica Gestáltica com Adolescentes: 0 Funcionamento do Processo Psicoterápico}

No atendimento psicoterápico com adolescentes, para Mirabella (2013), o gestalt-terapeuta busca facilitar ao adolescente a identificação consigo mes- 
mo, a distinção em relação às outras pessoas e ao mundo, a percepção como sujeito responsável por suas escolhas, avaliando assim as consequências e constituindo os seus valores a respeito do mundo.

No atendimento psicoterápico, o gestalt-terapeuta busca a compreensão de como ocorre a situação (processo descritivo) e não da explicação (Pinheiro, 2013). O foco é na presentificação das vivências do adolescente e de sua família em uma relação de interesse e de acolhimento, sem a presença de julgamentos.

Os adolescentes começam o atendimento psicoterápico por recomendaçãoda família ao perceber alguma alteração no comportamento do sujeito ou por indicação da escola ou por profissionais de saúde. Em alguns casos, os adolescentes podem procurar o atendimento por vontade própria. É importante destacar para a realização do processo psicoterápico que o adolescente tenha disponibilidade para compartilhar a sua história de vida e os seus conflitos com o psicoterapeuta. Ou ainda, que possa ter demanda e perceber um sentido para o processo terapêutico na sua vida.

Caso seja a família que procure o atendimento, o psicoterapeuta pode perceber se o adolescente tem desejo de realizar as sessões ou não. Caso ele não tenha, há a sugestão para a família para que o adolescente não permaneça em atendimento. Ele não pode realizar a psicoterapia por imposição ou sem perceber sentido para isto. Se isto ocorrer, podemos sugerir para os responsáveis para realizar o atendimento de orientação ao contexto familiar, conversando com os pais sobre as dificuldades que apresentam com o adolescente e percebendo as formas de atuar com o seu filho.

Se o motivo for a não identificação com o psicoterapeuta ou o não estabelecimento da relação terapêutica, recomenda-se que o adolescente procure um outro profissional. É fundamental que ocorra o estabelecimento do vínculo entre o adolescente e o psicoterapeuta, para que possa falar com confiança sobre os temas que o angustia.

É importante destacar que "a postura do psicoterapeuta varia com a maneira como o adolescente chega à terapia, mas a construção do vínculo afetivo e de confiança é fundamental ao processo" (Zanella \& Antony, 2016, p. 97). Os temas que são trabalhos no processo psicoterápico com adolescentes são provenientes da sua fase de desenvolvimento ou de problemáticas vividas no seu contexto social, escolar e familiar, como, por exemplo, a sexualidade, as dificuldades de relacionamento com os pais e a família, escolhas profissionais, uso de substâncias psicoativas, automutilação, transtornos alimentares, problemas relacionados a escola (aprendizagem, bullying, cyberbullying, violência entre professor e aluno), as ideações suicidas, entre outros.

[Os adolescentes têm] muitos sentimentos, lembranças e fantasias do passado, que interrompem o seu fluxo natural. Ele tem profundidade de sentimento que acha difícil de compartilhar com a sua família. Ele precisa de assistência para expressar seus sentimentos de ansiedade, solidão, frustração, auto depreciação, confusão sexual e medo. Ele precisa ver como pode assumir responsabilidade pela sua própria vida o máximo possível, e também como interrompe o seu próprio fluxo organísmico. (Oaklander, 1980, p. 321)

Nas primeiras sessões, podemos conhecer o campo existencial do adolescente, ou seja, sermos apresentados à escola, aos amigos, à família, à religião, à sexualidade, aos esportes e ao lazer (Zanella \& Antony, 2016). É essencial perguntar ao adolescente como se percebe neste período e como está vivenciando à esta fase.

Em certas ocasiões o próprio adolescente pede para entrar primeiro; em outras, os pais marcam a primeira entrevista; em outras ainda, a família toda entra junto. É interessante observar que a forma como eles chegam, mostra a configuração familiar. O importante na primeira sessão é que tenhamos entrevistas iniciais com os pais para conhecer a dinâmica familiar do ponto de vista deles, abrindo também a possibilidade de acolhê-los e orientá-los em suas incertezas. Inicia-se assim o trabalho do Gestalt-terapeuta. (Zanella \& Antony, 2016, p. 99)

Nas sessões com os adolescentes, segundo Mirabella (2013), é a oportunidade de entrar em contato com a sua história, ajudar no processo de identificação e diferenciação dos outros, acolher seus momentos de frustração e de dúvidas, dialogar sobre temas que geram incômodos e sofrimentos, partilhar segredos, compreender as suas escolhas, acompanhar o seu processo de desenvolvimento, confirmar os seus recursos, entre outros.

De acordo com Pinheiro (2013, p. 48) é essencial "identificar qual é a dor psíquica, que tipo de defesa o adolescente desenvolveu para lidar como a frustração de não conseguir realizar seu desejo.”

Nos encontros de orientação à família, é necessário que o gestalt-terapeuta promova a compreensão dos pais sobre o processo de desenvolvimento dos filhos, dialogue sobre momentos de disciplina e de liberdade, facilite estratégias de enfrentamento das dificuldades com os seus filhos, converse sobre suas ações e seus posicionamentos em relação aos filhos, reflita sobre o papel da família, da escola e dos amigos para os adolescentes e acolha o sofrimento psíquico dos familiares a respeito dos seus filhos.

Para Mirabella (2013) o gestalt-terapeuta deve perceber os conflitos existentes do autoritarismo dos pais em relação aos filhos e das situações de negligência ou abandono ou indiferença. Em alguns casos, os pais esquecem que já foram adolescentes, que entraram em contato com este período, em um contexto histórico, psicológico, econômico, social e cultural, que pode ser distinto de seu filho. O psicoterapeuta pode propiciar uma reflexão sobre a adolescência vivenciadas pelos pais e a compreensão da adolescência dos filhos na atualidade. 
Além destes encontros de aconselhamento à família, podemos realizar sessões conjuntas, para perceber a interação entre o adolescente e a sua família, ou de membros da sua família (por exemplo, apenas o seu pai e o adolescente, ou sua mãe e o adolescente, ou outras pessoas). Neste momento, o adolescente pode verbalizar para a família o que o incomoda e discutir sobre um assunto relevante, e vice-versa. Fernandes (2013, p. 36) afirma que as "minhas intervenções têm o propósito de ora de facilitar a comunicação entre eles, ora de auxiliá-los a encontrar novas perspectivas para que consigam equacionar, redefinir e elaborar conflitos e assim tomar decisões com mais consciência."

O gestalt-terapeuta deve estabelecer uma relação dialógica e uma atitude de presença com o jovem (Mirabella, 2013). Deve ter uma disponibilidade e interesse em atender este público, ou seja, sentir-se à vontade para conversar sobre as vivências do adolescente e conseguir acessá-lo com a sua atuação. Pinheiro (2013, p. 96) recomenda atitudes para o estabelecimento da relação terapêutica com os adolescentes: "abertura, empatia, reciprocidade, presença, responsabilidade.” Em uma postura de aceitação, de respeito e de confirmação do adolescente da forma que ele se apresenta para o gestalt-terapeuta.

No estabelecimento da relação terapêutica, o gestalt-terapeuta pode usar experimentos com o adolescente, com base nos conflitos vividos, nas situações inacabadas, na necessidade do cliente, propiciando-o disponibilidade e interesse pelo processo. Também pode ser usado para vivenciar situações inacabadas na sua vida, fornecer informações sobre o adolescente, favorecer o seu processo, entrar em contato, facilitar o discurso expressivo, entre outros.

\section{Gestalt-terapia: A Arte da Experimentação no Processo Terapêutico com Adolescentes}

Neste tópico, retrataremos o uso de experimentos na abordagem gestáltica, apresentando uma reflexão sobre a criatividade na atuação do gestalt-terapeuta, a concepção de experimentos na abordagem e os tipos de experimentos que podem ser utilizados no setting terapêutico.

Além disto, apontamos como pode ocorrer o uso do self-boxna clínica gestáltica com adolescente e a compreensão do self na abordagem, trazendo posicionamentos sobre o ciclo de contato e as especificidades da atuação do gestalt-terapeuta com o self-box com adolescentes, apresentando assim exemplos da prática clínica.

\section{1 - 0 Uso dos Experimentos na Gestalt-terapia}

A Gestalt-terapia, para Zinker (2007), é uma abordagem psicológica com um enfoque na expressão da criatividade do cliente por meio do encontro terapêutico, propiciando um processo de crescimento e de autoconhecimento. Neste sentido, o processo terapêutico tem um sentido artístico de experimentação. De acordo com Alvim e Ribeiro (2009, p. 37), "a Gestalt-terapia, que emergiu nos anos 50 e 60, com foco no experimento e na ação criativa, propunha trazer o sensível e o corpo para o setting terapêutico, indicando que a experiência era um importante referencial."

A concepção de pessoa na Gestalt-terapia, conforme Ribeiro (2011), é um ser relacional que estabelece contato com o mundo. O contato é criativo. É no contato que ocorre a awareness. Cardella (2002, p. 69) afirma que "a awareness implica sensação e percepção espontânea, sem esforço, com destaque de figuras que emergem a partir de necessidades prioritárias do indivíduo, num processo contínuo de formação figura-fundo.”

Nesta perspectiva, ser criativo na abordagem gestáltica é um convite para recriar as experiências na existência com os outros e com o mundo. A concepção de saúde baseia-se na possibilidade de encontrar novos caminhos com o mundo. Já, a concepção de adoecimento foca-se na repetição, na paralização e na estagnação de maneiras de ser com o mundo.

De acordo com Zinker (2007), a criatividade na Gestalt-terapia é um processo de transformação e de mudança no encontro entre psicoterapeuta e o cliente, ou seja, é desenvolver novos comportamentos para situações cristalizadas. O psicoterapeuta é um ser criativo no setting terapêutico que facilita a recriação de experiências e de situações inacabadas com o cliente, pois possibilita a inventividade de diversas situações de aprendizagem a partir do uso dos experimentos.

A gestalt-terapia é, na realidade, a permissão para ser criativo. Nossa ferramenta metodológica básica é o experimento, uma abordagem comportamental para passar a um novo patamar de funcionamento. $\mathrm{O}$ experimento se dirige ao cerne da resistência, transformando a rigidez em um suporte elástico para a pessoa. Não precisa ser pesado, sério, nem ter uma comprovação rigorosa; pode ser teatral, hilário, louco, transcendente, metafísico, engraçado. O experimento nos dá licença para sermos sacerdotes, prostitutas, gays, santos, sábios, magos - todas as coisas, seres e noções que se ocultam em nós. Os experimentos não precisam brotar de conceitos; podem começar simplesmente como brincadeiras e desencadear profundas revelações cognitivas. (Zinker, 2007, p. 30)

Os experimentos em Gestalt-terapia são ações intencionais do psicoterapeuta para o cliente vivenciar. É um convite ao cliente para se experienciar a partir de uma postura fenomenológica e dialógica em um contexto de aceitação, respeito e confiança. O psicoterapeuta deve ter clareza do que está propondo e o sentido de sua ação para o cliente como forma de facilitar o seu processo de dar-se conta.

Para Ribeiro (2006), uso dos experimentos no setting terapêutico propicia ao cliente a arte 
de se experimentar, tornando-o um experimento vivo, ou seja, o cliente é um sujeito ativo e seu próprio instrumento de trabalho. Desta forma, a sessão de psicoterapia é um experimento e o psicoterapeuta um facilitador deste processo. Desta maneira, para Zinker (2007, p. 51), "fazer terapia é como fazer arte”.

Enfatizamos que a realização do experimento pelo cliente não é obrigatória, pois o psicoterapeuta deve perceber a sua disponibilidade para desenvolvê-lo. Caso o cliente tenha interesse em efetuá-lo, pode interromper a qualquer momento, caso deseje. Assim, mesmo que comece, pode pará-lo a qualquer momento, de acordo com o seu limite.

Neste sentido, o psicoterapeuta deve ter uma atitude compreensiva e respeitosa em relação à recusa ou interrupção do cliente. E dependendo do caso, pode falar a respeito disto, ou mudar de assunto e falar de outro tema.

Segundo Rodrigues (2011), quando falamos sobre um determinado assunto é como se estivéssemos narrando uma história e não nos implicando com o que estamos vivenciando. O experimento possibilita descrever a situação vivenciada e reconstituí-la no presente. O sujeito integra diversas possibilidades, como, por exemplo, recordações, sensações, sentimentos, pensamentos, emoções, expressão corporal, respiração. Isto possibilita ao sujeito estar consciente do seu momento existencial e emocional, podendo assim produzir novos sentidos e novas formas de experienciar a situação.

$\mathrm{O}$ experimento tem como intuito facilitar a awareness do cliente, perceber a sua forma de funcionamento no momento, a ampliação/delimitação das fronteiras de contato, a integração de polaridades, a explorar suas resistências, a criação de novas possibilidades de atuar com o mundo, compreender as situações inacabadas e poder ressignificá-las.

Para Juliano (1999), o experimento é uma forma de emergir o que está presente no momento existencial do cliente. A facilitação ocorre a serviço do cliente e sua forma de expressão, com o intuito de focalizar em algo, ou mobilizar o fundo para que a figura se transforme, ou perceber novas formas de relacionamento, ou chamar atenção para a maneira que o corpo se expressa. É a capacidade de reconstruir histórias.

O experimento é um convite do terapeuta para o cliente experimentar uma situação inacabada no aqui e agora. Ao invés de usar as palavras, o cliente tem a oportunidade de agir. É uma outra forma de se expressar e a disponibilidade para arriscar em um ambiente seguro e acolhedor (Zinker, 2007).

O experimento é algo original na relação entre cliente e psicoterapeuta, é uma oportunidade de revivenciar seus sentimentos e ações abortados. Como é algo singular, o psicoterapeuta pode sugerir "novamente" o desenvolvimento da ação. Por exemplo, pode propor ao cliente em uma sessão para perceber um movimento ou para focalizar em um gesto e em outro momento solicitar "novamente" isto. A respeito disto, o que pode emergir em cada sessão é único e o cliente pode ter sensações e percepções diferentes em seu processo.

De acordo com Polster e Polster (2001) o experimento terapêutico na Gestalt-terapia conecta o falar, o sentir e o agir. É transformar o falar em fazer em que emergem sensações. Assim, não é uma reprodução de uma situação inacabada ou um treinamento para um evento futuro, mas experimentar no momento atual a sensação de fluidez com consciência para a sua ação.

O experimento é um evento dirigido pelo psicoterapeuta que possibilita confronto do sujeito consigo mesmo e suas questões em um ambiente seguro e acolhedor, ou seja, é sujeito e objeto de sua ação. O percurso realizado é escolhido e construído pelo cliente, havendo assim imprevisibilidade para o psicoterapeuta e o cliente (Zinker, 2007).

Percebemos que o que emerge tem intencionalidade para o cliente. Apresenta um caráter exploratório e vivencial para o sujeito, que propicia o reconhecimento de novas possibilidades de ação, trazendo o enfoque para a forma que o cliente vivencia este processo, e não penas para o conteúdo.

Para Zinker (2007), o psicoterapeuta facilita o processo do cliente tornar-se um experimentador, educador, transformador ativo de si mesmo e da sua realidade. No setting terapêutico, o cliente ousa criar e rompe os seus limites, conforme sua disponibilidade. Enfatizamos que o psicoterapeuta deve respeitar o tempo e o limite do cliente.

A amplitude desse experimento variará de acordo com o momento, como está sendo vivido e a fase em que o cliente se encontra. $\mathrm{O}$ experimento é qualquer coisa que aumente a consciência, e pode ser bem pequeno, como o espelhar de um gesto, o esclarecimento de algo que foi dito, uma simples pergunta ou comentário. A decisão de usar ou não o experimento dependerá grandemente da arte do terapeuta, de sua avaliação da fase em que o cliente se encontra, e de sua sensibilidade ao ritmo da proposta e sua habilidade para negociar. (Juliano, 1999, p. 42)

Os experimentos podem ser: a cadeira vazia, a amplificação, o self box, a fantasia dirigida e a viagem de fantasia, o trabalho corporal, a representação, identificação, a exageração, as metáforas etc. Pode ser o pedido para a edição de um sonho, transformar perguntas em afirmações, diálogo entre partes, fazer colocações específicas ao invés de generalizações pelo cliente. Podemos também pensar na escuta atenta e na intervenção verbal do psicoterapeuta. Enfim, é qualquer ato criado por este profissional para atender as necessidades do cliente.

Com o enfoque no objetivo deste artigo, destacamos o uso de um experimento na Gestalt-terapia com adolescentes: o self-box. 


\section{2- O Uso do Self-Box na Clínica Gestáltica com Adolescentes: A Compreensão de Self na Gestalt-terapia.}

O ciclo do contato mostra onde o cliente se encontra, revela quais são os fatores saudáveis e de adoecimento na sua relação com o mundo. O self é o processo de contatar, ou seja, constitui-se no contato com meio.

O ciclo do contato é um ciclo de experiências, é um clico de satisfações de necessidades. Neste ciclo, o self apresenta a forma que o contato funciona no encontro humano. O self regula o pensar, o agir, o sentir, o fazer e o falar humanos. Conhecendo a pessoa, pode-se conhecer o seu self. O self é como um negativo de uma fotografia, ele existe, mas necessita ser revelado. Esta revelação ocorre pelo contato (Ribeiro, 2007).

A Gestalt-terapia argumenta que é precisamente na fronteira de contato, o local de encontros entre Self e outro e de afastamento para ambos, que a psicologia pode explicar melhor, e os psicoterapeutas presenciar melhor e reportar aos pacientes a responsabilidade que as pessoas têm de moldar sua própria experiência. (Alvim e Ribeiro, 2009, p. 44)

Na Gestalt-terapia, o selfé um princípio organizador do processo de contato. É um sistema complexo de contatos necessários ao ajustamento criativo com o campo. É gerenciamento da existência, é a possibilidade de interação na fronteira de contato (é encontro e separação). É um processo pessoal e característico de sua maneira de reagir num dado momento. É agente de crescimento e desenvolvimento. É integrador e atualizador do potencial humano.

Para Ribeiro (2006, p. 170), "o self é uma estrutura cujo processo pretende revelar o íntimo funcionamento da personalidade ou da pessoa. É também um processo na e da pessoa, que indica um jeito peculiar e restrito de funcionar da personalidade". Assim, o self facilita a cada pessoa a percepção de si mesmo. De acordo com Ginger e Ginger (1995), o self não é uma instância fixa e determinada, pois é o ser com o mundo, que implica em um processo pessoal que pode ser transformado conforme o campo, a situação e o momento. É a nossa forma de agir e reagir com o mundo. O self compreende a função Id, Ego e Personalidade.

A função Id é a necessidade vital e os atos automáticos. É vinculado ao sistema sensório motor e associa-se às emoções básicas. São os gestos espontâneos. A função Ego é responsável por entrar ou evitar o contato. É a escolha ou rejeição de algo com o meio, percebendo o que é saudável, ou não. Corresponde ao funcionamento do self. A função Personalidade é a representação de si mesmo, é a autoimagem, é a constituição da identidade. É a forma como somos nas nossas interações sociais, ou seja, é a maneira particular de agir com o mundo (Ribeiro, 2006).

Ao atender adolescentes, o psicoterapeuta revisita a sua adolescência, trazendo reflexões sobre as suas descobertas e os conflitos de sua vivência na sua psicoterapia. O psicoterapeuta é tocado em suas experiências e pode emergir situações inacabadas deste período que precisam ser trabalhadas na sua psicoterapia e serem dialogadas na sua supervisão. No trabalho com adolescentes, podem ser usados experimentos como: o desenho de como se sentem em relação aos seus corpos, pintar como se sentem em referência a sua sexualidade, trabalhar com poemas que contenham assuntos do interesse do adolescente, expressar-se por meio de fantasias, entre outros (Oaklander, 1980). Reforçando este posicionamento, destacamos que:

o terapeuta deve ser criativo e atento às necessidades do cliente durante as sessões. De acordo com o tema de cada encontro, proporá experimentos que facilitem a expressão das dificuldades, possibilidades e emoções do cliente, bem como o contato com elas. Podemos utilizar fotografias, desenhos, tintas, argila, telas, filmes, desenho do contorno do corpo, colagem, textos, frases a completar, signos do zodíaco, cartas de tarô, enfim, tudo que possa facilitar o contato do adolescente com seus conflitos, dificuldades, potencialidades e características da personalidade. Os jogos de tabuleiro também constituem excelente recurso para trabalhar frustrações, cooperação e competitividade. (Zanella \& Antony, 2016, p. 102)

No trabalho com adolescentes, o self-box (a caixa do eu) facilita o processo contínuo de conscientização do cliente, ou seja, que se torne consciente da sua forma de entrar em contato consigo mesmo e com o mundo no momento presente. Diante da concepção de self na Gestalt-terapia, o self-box possibilita ao adolescente revelar a si mesmo e sua forma de funcionar consigo mesmo, com os outros e com o mundo.

Self-box - a caixa do eu - é um recurso ludoartístico em que a pessoa coloca dentro de uma caixa objetos e fotos que são importantes para ela, compartilhando esse conteúdo com o terapeuta. Trata-se de uma ferramenta interessante, uma vez que o adolescente, muitas vezes pede opinião de colegas, pais e professores sobre o que colocar na caixa. Ao entrar em contato com tais objetos, ele revisita sua história e a reconfigura. (Zanella \& Antony, 2016, p. 105)

Para Zanella e Zanini (2013), os adolescentes podem pedir para amigos e colegas emprestarem objetos particulares e fotos do grupo e com pessoas significativas. Em alguns casos, podem solicitar a família e amigos a seleção dos objetos para levar a psicoterapia. Por exemplo, no começo de uma sessão com uma adolescente, ela me fala que pediu para sua mãe ajudar na escolha dos objetos. A adolescente conversa sobre os objetos trazidos. Observo que tem alguns na caixa que ela não falou. E pontuo isto. Ela comenta que escolheu falar apenas sobre os objetos selecionados por ela e não por 
sua mãe. No momento inicial, ela relata que estava insegura em relação ao que levar e pede sugestão de um familiar. Embora perceba a necessidade da adolescente em distinguir-se do ambiente familiar e buscar suas escolhas com responsabilidade.

A caixa do self é um recurso que os adolescentes recebem muito bem. Pode ser feita em casa e levada no consultório ou ser feita no próprio consultório. Pede-se ao jovem que coloque na caixa objetos que possam representá-lo, ou mesmo que crie um tema com a caixa: a caixa dos sentimentos, a caixa da vida escolar, do amor, etc. (Zanella \& Zanini, 2013, p. 75)

Desta forma, o gestalt-terapeuta pode pedir para o adolescente elaborar a sua caixa na sessão, ou ser uma atividade psicoterapêutica de casa. Quando o psicoterapeuta sugere que realize na sessão, pode usar os objetos presentes na bolsa e/ou na sala, como também pode pedir para desenhar os objetos e colocar na caixa. Quando solicita que faça em casa, possibilita o adolescente ter momentos reflexivos no ambiente familiar, entrar em contato com objetos e elementos que são significativos para a sua história de vida que fazem parte do momento atual, que podem ser levados para o próximo atendimento.

$\mathrm{O}$ gestalt-terapeuta pode recomendar que o cliente selecione um tema para construir a sua caixa, ou o profissional pode sugerir um assunto, ou pode deixar que o cliente escolha livremente da maneira que desejar. Isto depende da forma de condução do psicoterapeuta e da disponibilidade do cliente.

De acordo com a concepção de self na Gestalt-terapia, podemos refletir que o self-box permite que o adolescente perceba a maneira como se apresenta no mundo no momento atual, considerando o tempo e o espaço. A partir da sensibilidade do psicoterapeuta e da figura que emerge na relação, o adolescente é convidado a se conhecer mais e se apresentar de uma forma diferente para o gestalt-terapeuta. O self-box é um material para trabalhar as identificações do cliente consigo mesmo, com os outros e com o mundo, pois o adolescente pode levar ao setting terapêutico objetos, fotos, livros, peças de roupas, acessórios, cartas, bilhetes, brinquedos, CDS e DVDS, que trazem representações dos seus gostos e de suas características pessoais.

$\mathrm{Na}$ minha prática profissional, podemos exemplificar isto com uma adolescente que sofria bullying na escola e trouxe um papel de bombom que um colega deu para ela. Houve uma brincadeira na escola e ela ganhou um pacote de bala. Era para levar chocolate para um colega, mas esta pessoa percebeu que ela comia no intervalo a bala e preferiu levar. Ela gostou muito da atitude do colega e levou para que possamos falar sobre a importância da amizade na sua vida.

Cuidar para que o jovem melhore sua autoestima e se fortaleça é crucial no trabalho psi- coterapêutico. Integrar novas figuras em seu mundo e amadurecer para aceitar frustrações próprias do percurso da vida faz parte do desenvolvimento. Facilitar ao adolescente essa compreensão é uma tarefa de ampliação da awareness. O trabalho com a self-box pode ajudá-lo a resgatar e revisitar sua história de vida. (Zanella \& Antony, 2016, p. 105)

Este material propicia aos adolescentes falarem de si mesmos, descreverem experiências, abordarem a sua infância, retratarem particularidades de sua família, falarem sobre seus sonhos e seus projetos, perceberem a sua forma de funcionamento, compreenderem as suas limitações de relacionamento com o outro, entre outros.

Na minha experiência clínica, por exemplo, com uma adolescente que apresenta bulimia, quando solicitei que me trouxesse a caixa do eu com materiais que a representassem, mostra-me a cartela com seu primeiro laxante. Inicialmente, ela fala que não sabe o motivo de guardá-lo. Ela afirma que começou a usar por prisão de ventre, mas quando começou a perceber que perdia peso ao tomá-lo, começou a fazer uso do medicamento com grande frequência até que sua família percebesse e o proibisse.

Na condução do processo psicoterápico, o gestalt-terapeuta pode coletar informações, compreender os interesses e os gostos (religião, cor preferida, estilo musical, signos, filmes, séries, livros), conhecer sobre a sua família, resgatar elementos da infância que estão presentes, entre outros. É a oportunidade de compartilhar sua vida e suas experiências com o psicoterapeuta.

Na minha experiência profissional, é uma sessão em que o adolescente coloca-se bastante trazendo especificidades de sua vida que até o momento não eram conhecidas. Em um caso atendido, uma adolescente mostra um urso e fala que quando está triste gosta de apertá-lo, ou chora com o urso. É importante perceber a representatividade deste objeto para a cliente. Relata que quando apresenta dificuldades, morde os lábios ou chora no banheiro. Embora, tenha vontade de bater. Neste momento, ela descreve pela primeira vez as suas tentativas de suicídio.

O gestalt-terapeuta pode solicitar que o cliente ao trazer os objetos da caixa, fale no presente e em primeira pessoa, pode falar como se fosse um objeto da caixa, ou pode estabelecer um diálogo entre elementos da caixa, ou descrever uma experiência e outras possibilidades de atuação. Assim, "ao se basear na experimentação, fazendo uma passagem da explicação para a experiência, a Gestalt-terapia permite que o ato psicoterápico seja um campo de experiência” (Alvim \& Ribeiro, 2009, p. 39)

Desta forma, quando o psicoterapeuta sugere a atividade, o cliente pode não levar o material para a sessão, caso não se sinta à vontade ou não deseje realizá-lo. Pode ter interesse em conversar sobre o fato de não ter levado o material, ou ter a necessidade de falar sobre outro assunto.

Na minha experiência clínica, sugeri para uma adolescente preparar a caixa em casa e levar no pró- 
ximo encontro. A adolescente fez isto, mas esqueceu o material. Antes do começar a sessão, ela pede para a sua mãe tirar fotos da caixa e mandar para o seu WhatsApp. Na sessão, ela me relata o fato. Percebo a sua preocupação e o seu interesse em me mostrar os objetos da caixa por meio de fotos. Foi uma sessão bem marcante, pois a adolescente sentou no chão (em um ato espontâneo) ao lado na minha cadeira, mostrando as fotos tiradas pela mãe e relatando sobre a sua vida e sua história. O diálogo ocorreu a partir das imagens no celular.

Ressalto então a importância do uso do self-box no trabalho com adolescentes na Gestalt-terapia, promovendo o interesse pelo processo terapêutico, a aproximação com o terapeuta, a possibilidade de ressignificar as situações inacabadas do cliente na presença e no acolhimento do gestalt-terapeuta.

\section{Considerações Finais}

Este artigo é relevante por apresentar um estudo sobre o uso do self-box na atuação do gestalt-terapeuta com adolescentes, perpassando assim a constituição da adolescência, a clínica gestáltica com adolescentes e o uso de experimentos na Gestalt-terapia. É uma maneira de trabalhar diversos temas com este público, gerando assim uma vinculação com o psicoterapeuta e a adesão ao tratamento.

Diante da concepção de self na Gestalt-terapia, o uso do self-boxpossibilita o autoconhecimento, a percepção sobre a sua forma de funcionamento, o reconhecimento de suas limitações, a maneira como entra em contato consigo mesmo, com os outros e com o mundo.

Os psicólogos clínicos necessitam realizar estudos e pesquisas que promovam a divulgação dos trabalhos realizados no âmbito profissional, trazendo assim novos conhecimentos sobre a prática clínica. Precisamos incentivar o desenvolvimento de pesquisas e troca de experiências acerta da clínica com adolescentes.

Além disto, é fundamental que os gestalt-terapeutas, em uma perspectiva criativa, possam compartilhar e aprofundar os estudos com o uso de experimentos na abordagem. Neste caso, podemos perceber que com a articulação teórica e a presença de experiências clínicas sobre o uso de self-box na clínica gestáltica com os adolescentes.

\section{Referências}

Aberastury, A. \& Knobel M. (1981). Adolescência normal: um enfoque psicanalítico. Porto Alegre: Artmed.

Alvim, M. B. \& Ribeiro, J. P. (2009). O lugar da experimentação no trabalho clínico em Gestalt-Terapia. Estudos e Pesquisas em Psicologia, 9 (1), 37-58. Baroncelli, L. (2012). Adolescência: fenômeno singular e de campo. Revista da Abordagem Gestáltica, 18 (2), 188-196.

Brasil (2005). Estatuto da Criança e do Adolescente. Brasília: MEC.
Cardella, B H. P. (2014). Ajustamento criativo e hierarquia de valores ou necessidades. In: Frazão, L. M \& Fukumistu, K. O. (Orgs). Gestalt-terapia: conceitos fundamentais (pp. 104-130). São Paulo: Summus.

Cardella, B. H. P. (2002) A construção do psicoterapeuta: uma abordagem gestáltica. São Paulo: Summus.

Erikson, E. (1987). Identidade, Juventude e Crise. Rio de Janeiro: Editora Guanabara.

Fernandes, M. B. (2013). A consulta clínica com pais de adolescentes em Gestalt-terapia. In: Zanella, R. (Org.). A Clínica Gestáltica com Adolescentes: caminhos clínicos e institucionais. (pp. 31-58) São Paulo: Summus.

Ginger, S. \& Ginger, A. (1995) A. Gestalt: uma terapia do contato. São Paulo: Summus.

Juliano, J. C. (1999). A arte de restauras histórias: o diálogo criativo no caminho pessoal. São Paulo: Summus.

Lima, T. C. S. \& Mioto, R. C. (2007). Procedimentos metodológicos na construção do conhecimento científico: a pesquisa bibliográfica. Revista Katálysis, 10, 37-45.

Mirabella, A. M. (2013). Afetividade na adolescência. In: Zanella, R. (Org.) A Clínica Gestáltica com Adolescentes: caminhos clínicos e institucionais. (pp. 11-30) São Paulo: Summus.

Oaklander, V. (1980). Descobrindo Crianças: A abordagem gestáltica com crianças e adolescentes. São Paulo: Summus.

Outeiral, J. O. (1994). Adolescer: Estudos sobre adolescência. Porto Alegre: Artes Médicas.

Perls, F. S. (2011). A Abordagem Gestáltica e testemunha ocular da terapia. Rio de Janeiro: LTC.

Pinheiro, L. (2013). Adolescentes? Dá para atender. In Zanella, R. (Org.). A Clínica Gestáltica com Adolescentes: caminhos clínicos e institucionais. (pp. 77104). São Paulo: Summus.

Polster, E. \& Polster, M. (2001). Gestalt-terapia Integrada São Paulo: Summus.

Ribeiro, J. P. (2006). Vade-Mécum de Gestalt-terapia: Conceitos Básicos. São Paulo: Summus.

Ribeiro, J. P. (2007). O ciclo do contato: temas básicos na abordagem gestáltica. São Paulo: Summus.

Ribeiro, J. P. (2011). O conceito de mundo e de pessoa em Gestalt-terapia: Revisitando o caminho. São Paulo: Summus.

Rodrigues, H. E. (2011). Introdução à Gestalt-terapia: conversando sobre os fundamentos da abordagem gestáltica. Petrópolis: Vozes.

Silva, R.V.B. (2015). Os Conflitos na Fronteira de Contato entre Pais e Filhos Adolescentes. Revista IGT na Rede, 12 (22), 53-66. 
Zanella, R. \& Antony, S. (2016) Trabalhando com adolescentes: (re)construindo o contato com o novo eu emergente. In: Frazão, L.M. \& Fukumistu, K.O. (Orgs). Modalidades de intervenção em clínica em Gestalt-terapia. (pp. 83-109). São Paulo: Summus.

Zanella, R. \& Zanini, M. E. B. (2013). Atendendo adolescentes na contemporaneidade. In: Zanella, R. (Org.). A Clínica Gestáltica com Adolescentes: caminhos clínicos e institucionais. (pp. 59-76). São Paulo: Summus.

Zinker, J. (2007). Processo criativo em Gestalt-terapia. São Paulo: Summus.

Deyseane Maria Araújo Lima é Doutora em Educação. Mestre em Psicologia. Especialista em Psicologia Clínica (CFP). Especialista em Educação à Distância. Especialista em Educação Inclusiva. Formação em Gestalt-terapia. Formação em Gestalt-terapia com crianças e adolescentes. Formação em Gestalt-terapia com casais e famílias. Diretora da Vincular: Estudos, Pesquisa e Psicoterapia. Professora da graduação e pós-graduação em psicologia. Psicóloga Clínica. Atualmente leciona no Curso de Psicologia do Centro Universitário Christus (Unichristus), e é Diretora da Clínica Vincular. E-mail: deyseanelima@yahoo.com.br

Recebido em 06.06.17

Primeira decisão editorial em 24.08.17

Segunda decisão editorial 14.04.2018

Aceito em 17.08.18 